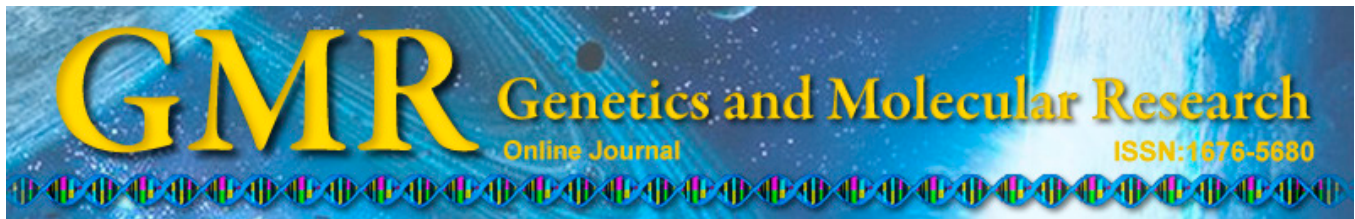

\title{
Association of $T U S C 3$ gene polymorphisms with non-syndromic mental retardation based on nuclear families in the Qinba mountain area of China
}

\author{
M.J. Zhang ${ }^{1 *}$, L.X. Xing ${ }^{1 *}$, M. Cui ${ }^{2}$, X. Yang ${ }^{1}$, J.G. Shi ${ }^{2}$, J. Li ${ }^{3}$, \\ K.J. Zhang ${ }^{1}$, Z.J. Zheng ${ }^{3}$, F.C. Zhang ${ }^{1,3}$, J.L. Li ${ }^{1}$ and X.C. Gao ${ }^{1,3}$ \\ ${ }^{1}$ Key Laboratory of Resource Biology and Biotechnology in Western China, \\ Ministry of Education, Institute of Population and Health, \\ College of Life Science, Northwest University, Xi'an, Shaanxi, China \\ ${ }^{2}$ The Mental Health Center of Xi'an, Xi'an, Shaanxi, China \\ ${ }^{3}$ Institute of Application Psychology, College of Public Management, \\ Northwest University, Xi' an, Shaanxi, China \\ *These authors contributed equally to this study. \\ Corresponding authors: X.C. Gao/J.L. Li \\ E-mail: gaoxc@nwu.edu.cn / 1j1@nwu.edu.cn
}

Genet. Mol. Res. 14 (2): 5022-5030 (2015)

Received August 8, 2014

Accepted December 10, 2014

Published May 12, 2015

DOI http://dx.doi.org/10.4238/2015.May.12.5

\begin{abstract}
TUSC 3 interacts with the protein phosphatase 1 and magnesium ion transport system, which plays an important role in learning and memory. Abnormal conditions of learning and memory are common clinical characteristics of mental retardation (MR). However, the association of TUSC3 genetic polymorphisms with MR remains unknown. A total of 456 DNA samples including 174 nuclear families containing MR were collected in the Qinba mountain area of China. The genotypes of eight tag single nucleotide polymorphisms of TUSC3 were evaluated with traditional genetic methods. Familybased association tests, transmission disequilibrium tests (TDTs), and
\end{abstract}


haplotype relative risk (HRR) analyses were performed to investigate the association between genetic variants of the TUSC3 gene and MR. The genetic polymorphisms rs10093881, rs6530893, and rs6994908 were associated with MR (all P values $<0.05$ ) based upon the results of single-site TDT and HRR analyses. The haplotype block consisting of rs6530893 and rs6994908, harboring the sixth exon of TUSC3, was also associated with MR (all P values $<0.05$ ). This study demonstrated an association between genetic polymorphisms of the TUSC3 gene and MR in the Qinba mountain area, the sixth exon of which might contribute to the risk of MR. However, further studies are needed on the causal mechanisms in this association.

Key words: Tumor suppressor candidate 3; Mental retardation; Nuclear family; Single nucleotide polymorphisms

\section{INTRODUCTION}

Mental retardation (MR) is a group of heterogeneous neuropsychiatric disorders, defined as significant limitations both in intellectual functioning and in social adaptive behavior with onset before the age of 18 years in affected subjects. Of the general population, its prevalence is confirmed as between 1 and 2\% (Krahn and Fox, 2014). However, the morbidity reaches $3.19 \%$ in the Qinba mountain area in China. MR occurs locally in a familial clustering manner, which suggests that genetic abnormalities may play a critical role. More than 100 genes have been identified to be associated with X-linked mental retardation in recent years (Lubs et al., 2012), including FMR1 (Guruju et al., 2009), MECP2, GDI1, OPHN1, PAK3, and ILIRAPL1, among others. However, identification of the genes responsible for autosomal recessive mental retardation (ARMR) has advanced in a slow and laborious manner. To date, only approximately 10 genes have been identified (Afroze and Chaudhry, 2013), including PRSS12 (Molinari et al., 2002; Didelot et al., 2006), CRBN (Higgins et al., 2004), CC2D1A (Basel-Vanagaite et al., 2006), CC2D2A (Noor et al., 2008), GRIK2 (Motazacker et al., 2007), and tumor suppressor candidate 3 (TUSC3) (Garshasbi et al., 2008; Molinari et al., 2008). Although, numerous genes related to MR have been identified, understanding the biological basis of heterogeneous MR is still an enormous challenge. We still have limited information about genetic heterogeneity and the relationship between genotypes and phenotypes in the affected brains. Recent progress in the field of genetics provides us with an opportunity and clues to understand the molecular and genetic bases of MR (Inlow and Restifo, 2004). However, these candidate genes still await investigation to confirm their roles in different MR populations.

TUSC3 was originally identified as a tumor suppressor gene within a homozygousdeleted region in pancreatic cancer (Bashyam et al., 2005), located on chromosome 8p22. In 2008, TUSC3 was first reported to be associated with ARMR (Garshasbi et al., 2008; Molinari et al., 2008). Subsequently, in a large Pakistani family, a second novel deletion mutation was reported (Khan et al., 2011). Later, a fourth mutation has been identified in the TUSC3 gene among Iranian population (Garshasbi et al., 2011). To date, a third deletion mutation was reported in an Italian patient with MR (Loddo et al., 2013). Controversially, the TUSC3 gene was excluded from consideration using polymorphic microsatellite and statistical analysis in four Tunisian families, likely due to the extreme heterogeneity of ARMR (Mhamdi et al., 
2011). Therefore, although TUSC3 was suggested as the fifth gene to be associated with nonsyndromic ARMR (Garshasbi et al., 2011; Afroze and Chaudhry, 2013), it remains a challenging task to screen and confirm this candidate gene, requiring investigation of different populations in multiple research cohorts. Therefore, we investigated the possible association between the TUSC3 gene and ARMR in the Qinba mountain area with a nuclear family sample, which will eliminate or reduce the effect of heterogeneity of ARMR, in order to confirm the relationship between the TUSC3 gene and ARMR.

\section{MATERIAL AND METHODS}

\section{Subjects}

The intelligence levels of children aged 4 to 5 and 6 to 16 years were evaluated using the Chinese Wechsler young children scale of intelligence (C-WYCSI, 1992) (Gong and Dai, 1992) and the Chinese Wechsler intelligence scale for children (C-WICS, 1993) (Gong and Cai, 1993), respectively. The social disability scores of participants were assessed using the adaptive scale for infants and children (Zuo et al., 1988). The intelligence quotient (IQ) and social disability scores of each patient with MR were determined to be $<70$ and $\leq 8$, respectively. The adult values were estimated by the Chinese classification of mental disorders, 2nd revision (CCMD-2-R) (Chen, 2002). Physical examination, behavior check, medical history investigation, and necessary examinations in laboratory were performed to exclude other etiologies such as infection, trauma, dystrophia, toxicosis, cerebral palsy, and birth complications, among others.

\section{DNA isolation}

The children with an IQ less than 75 were considered as probands and were recruited together with their parents. A total of 456 samples from 174 nuclear families with MR in the Qinba mountain area were collected. Peripheral blood samples were collected from all participants. Genomic DNA was extracted from peripheral blood using a modified phenol/chloroform method. DNA was stored at $4^{\circ} \mathrm{C}$ until the samples were further processed. The whole study was approved by the Ethics Committee of the National Human Genome Center, and was performed with previous consent of the participants.

\section{Single nucleotide polymorphism (SNP) selection and genotyping}

Tag SNPs were screened using the HapMap Genome Browser and Haploview version 4.1 software (Barrett et al., 2005). The criterion for tagging was set at $\mathrm{r}^{2}>0.8$ and Han Chinese in Beijing minor allele frequency $>0.1$. If a tag failed genotyping, an alternative tag SNP was chosen. Finally, eight SNPs of the TUSC3 gene, rs12677098, rs10093881, rs1035972, rs6530893, rs6994908, rs1421244, rs11989862, and rs352808, were selected. Primers were designed with the Primer Premier Version 5.0 software (http://www.premierbiosoft.com). The length of the polymerase chain reaction (PCR) products and the sequencing primers are shown in Table 1. The PCR-single-strand conformation polymorphism method was used for genotyping of the eight SNPs; the detailed information is shown in Table 1. PCR was carried out in a total volume of $10 \mu \mathrm{L}$ containing $0.8 \mu \mathrm{L}$ template DNA $(20 \mathrm{ng} / \mu \mathrm{L}), 5 \mu \mathrm{L} 2 \mathrm{X}$ Taq PCR Master 
Mix, $0.2 \mu \mathrm{L}$ of each primer $(10 \mu \mathrm{M})$, and $3.8 \mu \mathrm{L} \mathrm{ddH}_{2} \mathrm{O}$. The PCR products were amplified with an initial $5 \mathrm{~min}$ denaturation at $95^{\circ} \mathrm{C}$, followed by the corresponding cycles at $95^{\circ} \mathrm{C}$ for 30 $\mathrm{s}$, at the corresponding annealing temperature (see Table 1) for $30 \mathrm{~s}, 72^{\circ} \mathrm{C}$ for the corresponding time, and a final extension period at $72^{\circ} \mathrm{C}$ for $5 \mathrm{~min}$. Each $2 \mu \mathrm{L}$ PCR product sample was mixed with $8 \mu \mathrm{L}$ denaturing loading buffer (containing $95 \%$ formamide, $0.25 \%$ xylenocyanol, $0.25 \%$ bromophenol blue, and $10 \mathrm{mM}$ ethylenediaminetetraacetic acid, $\mathrm{pH} 8.0$ ), denatured at $98^{\circ} \mathrm{C}$ for $10 \mathrm{~min}$, and then rapidly cooled to $-20^{\circ} \mathrm{C}$. The DNA fragments were separated by electrophoresis on the corresponding polyacrylamide gel and observed by silver staining. After genotyping, six randomly selected samples were sequenced to determine the alleles for the genotyping results. For quality control, $10 \%$ random samples were repeated and showed $100 \%$ concordance for all polymorphisms.

Table 1. Eight SNPs of the TUSC3 gene and their corresponding PCR amplification information.

\begin{tabular}{|c|c|c|c|c|c|c|}
\hline SNP & Position & Allele & Primer orientation & Primer sequences $\left(5^{\prime}-3^{\prime}\right)$ & $\begin{array}{l}\text { PCR product } \\
\text { (bp) }\end{array}$ & $\begin{array}{c}\text { Annealing } \\
\text { temperature }\left({ }^{\circ} \mathrm{C}\right)\end{array}$ \\
\hline rs 12677098 & TUSC3 upstream & $\mathrm{G} / \mathrm{A}$ & $\begin{array}{l}\text { Forward } \\
\text { Reverse }\end{array}$ & $\begin{array}{l}\text { AGCCTCAGTCTTGGAATA } \\
\text { ATGCTTTGGGAGACCTA }\end{array}$ & 154 & 56.0 \\
\hline rs10093881 & Intron 1 & $\mathrm{~T} / \mathrm{C}$ & $\begin{array}{l}\text { Forward } \\
\text { Reverse }\end{array}$ & $\begin{array}{l}\text { ATTGTGTGTGGTGTGTGTCT } \\
\text { GGAAATCAAGCAGGGTAA }\end{array}$ & 149 & 50.4 \\
\hline rs 1035972 & Intron 2 & $\mathrm{G} / \mathrm{A}$ & $\begin{array}{l}\text { Forward } \\
\text { Reverse }\end{array}$ & $\begin{array}{l}\text { CCCTCATCATAGTCCACCATA } \\
\text { TAACTGCTTTGTAGATGCTTCA }\end{array}$ & 161 & 50.0 \\
\hline rs6530893 & Intron 5 & $\mathrm{C} / \mathrm{T}$ & $\begin{array}{l}\text { Forward } \\
\text { Reverse }\end{array}$ & $\begin{array}{l}\text { CAGAGGCTCACAGCTAATA } \\
\text { TGCCCAAGGTAAGAAAC }\end{array}$ & 187 & 53.0 \\
\hline rs6994908 & Intron 6 & $\mathrm{C} / \mathrm{T}$ & $\begin{array}{l}\text { Forward } \\
\text { Reverse }\end{array}$ & $\begin{array}{l}\text { GGAAGCAATTTTAGAGCA } \\
\text { GGGAGACAGAGTATAGGGA }\end{array}$ & 147 & 53.0 \\
\hline rs1421244 & Intron 8 & $\mathrm{C} / \mathrm{A}$ & $\begin{array}{l}\text { Forward } \\
\text { Reverse }\end{array}$ & $\begin{array}{l}\text { CTTTAATTGGCTCAG } \\
\text { CTCATTTCCTTTTTAG }\end{array}$ & 168 & 46.0 \\
\hline rs11989862 & Intron 9 & $\mathrm{C} / \mathrm{T}$ & $\begin{array}{l}\text { Forward } \\
\text { Reverse }\end{array}$ & $\begin{array}{l}\text { ATGGTGTGATGATCAGCC } \\
\text { AGACGATGGTGCCTTTAC }\end{array}$ & 161 & 58.0 \\
\hline rs352808 & Intron 10 & $\mathrm{C} / \mathrm{G}$ & $\begin{array}{l}\text { Forward } \\
\text { Reverse }\end{array}$ & $\begin{array}{l}\text { AATCCCTAGTTTTAAGTATCA } \\
\text { CTGTGGCATTATGTTTTG }\end{array}$ & 154 & 50.4 \\
\hline
\end{tabular}

$\mathrm{SNP}=$ single nucleotide polymorphism; TUSC3 = tumor suppressor candidate 3 ; $\mathrm{PCR}=$ polymerase chain reaction.

\section{Statistical analysis}

Hardy-Weinberg equilibrium was assessed using FINETTI (http://ihg.gsf.de/cgi-bin/ hw/hwa1.pl). Linkage disequilibrium (LD) was calculated, and haplotypes were constructed with Haploview version 4.1. Single-site and haplotype transmission disequilibrium tests (TDTs) and haplotype relative risk (HRR) analyses were performed with Haploview version 4.1 and UNPHASED version 3.0.13 (Dudbridge, 2003). The multiple testing correction of $\mathrm{P}$ values was performed by the positive-false discovery rate (FDR $q$ value) by $\mathrm{R}$ with the $\mathrm{Q}$ value software (Storey and Tibshirani, 2003). Statistical power analysis was performed using Quanto1.2.4 (Millstein et al., 2006). Statistical significance was set at $\mathrm{P}<0.05$.

\section{RESULTS}

The genotype frequencies of all SNPs were in Hardy-Weinberg equilibrium $(\mathrm{P}>0.05)$. Single-site TDT demonstrated that each one of the alleles was significantly over-transmitted in the patient group for rs10093881 ( $\mathrm{P}=0.0411)$, rs6530893 $(\mathrm{P}=0.0075)$ and $\mathrm{rs} 6994908$ $(\mathrm{P}=0.0084)$ sites (Table 2). Both rs6530893 and rs6994908 sites remained significant after 
multiple corrections (all FDR $q$ values $<0.05$ ). The HRR analysis also showed a similar trend for rs10093881, rs6530893, and rs6994908 sites $(\mathrm{P}=0.0405,0.0069$, and 0.0081, respectively) (Table 3). After correction, a positive result was supported by the allele frequencies of both rs6530893 and rs6994908 between the subjects and the virtual control (all FDR $q$ value $<0.05)$.

Table 2. Single-marker TDT analysis results for the TUSC3 gene.

\begin{tabular}{|c|c|c|c|c|c|c|c|c|}
\hline$\overline{\mathrm{SNP}}$ & Family trios & $\%$ Genotypes & Over-transmitted & Transmitted & Untransmitted & $\chi^{2}$ & $P$ & $q$ \\
\hline rs12677098 & 112 & 85.4 & G & 60 & 57 & 0.077 & 0.7815 & 0.7285 \\
\hline rs10093881 & 115 & 81.5 & $\mathrm{~T}$ & 69 & 47 & 4.172 & 0.0411 & 0.0859 \\
\hline rs1035972 & 119 & 89.0 & A & 75 & 65 & 0.714 & 0.3980 & 0.4810 \\
\hline rs6530893 & 130 & 93.4 & $\mathrm{~T}$ & 38 & 18 & 7.143 & 0.0075 & 0.0235 \\
\hline rs6994908 & 126 & 92.7 & $\mathrm{~T}$ & 75 & 46 & 6.950 & 0.0084 & 0.0235 \\
\hline rs1421244 & 122 & 89.4 & $\mathrm{C}$ & 52 & 51 & 0.010 & 0.9215 & 0.7731 \\
\hline rs11989862 & 119 & 87.1 & C & 58 & 55 & 0.080 & 0.7778 & 0.7285 \\
\hline rs352808 & 129 & 93.2 & G & 62 & 53 & 0.704 & 0.4013 & 0.4810 \\
\hline
\end{tabular}

TDT $=$ transmission disequilibrium test; TUSC3 = tumor suppressor candidate $3 ; \mathrm{SNP}=$ single nucleotide polymorphism.

\begin{tabular}{|c|c|c|c|c|c|c|c|c|c|c|c|}
\hline SNP & Allele & Transmitted & Untransmitted & $\begin{array}{l}\text { Frequency of } \\
\text { transmission }\end{array}$ & $\begin{array}{c}\text { Frequency of } \\
\text { non-transmission }\end{array}$ & Odds ratio & $95 \%$ Lo & $95 \% \mathrm{Hi}$ & $\chi^{2}$ & $P$ & $q$ \\
\hline \multirow[t]{2}{*}{ rs12677098 } & A & 70 & 73 & 0.3125 & 0.3259 & 1 & 1 & 1 & 0.0769 & 0.7815 & 0.7285 \\
\hline & G & 154 & 151 & 0.6875 & 0.6741 & 1.0530 & 0.7325 & 1.5130 & & & \\
\hline \multirow[t]{2}{*}{ rs10093881 } & $\mathrm{T}$ & 172 & 150 & 0.7478 & 0.6522 & 1 & 1 & 1 & 4.1980 & 0.0405 & 0.0859 \\
\hline & $\mathrm{C}$ & 58 & 80 & 0.2522 & 0.3478 & 0.6812 & 0.4702 & 0.9868 & & & \\
\hline \multirow[t]{2}{*}{ rs1035972 } & A & 132 & 122 & 0.5546 & 0.5126 & 1 & 1 & 1 & 0.7149 & 0.3978 & 0.4810 \\
\hline & $\mathrm{G}$ & 106 & 116 & 0.4454 & 0.4874 & 0.8667 & 0.6217 & 1.2080 & & & \\
\hline \multirow[t]{2}{*}{ rs6530893 } & $\mathrm{T}$ & 237 & 217 & 0.9115 & 0.8346 & 1 & 1 & 1 & 7.3030 & 0.0069 & 0.0235 \\
\hline & $\mathrm{C}$ & 23 & 43 & 0.08846 & 0.1654 & 0.4737 & 0.2704 & 0.8299 & & & \\
\hline \multirow[t]{2}{*}{ rs6994908 } & $\mathrm{T}$ & 195 & 166 & 0.7738 & 0.6587 & 1 & 1 & 1 & 7.0190 & 0.0081 & 0.0235 \\
\hline & $\mathrm{C}$ & 57 & 86 & 0.2262 & 0.3413 & 0.6133 & 0.4249 & 0.8853 & & & \\
\hline \multirow[t]{2}{*}{ rs1421244 } & A & 175 & 176 & 0.7172 & 0.7213 & 1 & 1 & 1 & 0.0097 & 0.9215 & 0.7731 \\
\hline & $\mathrm{C}$ & 69 & 68 & 0.2828 & 0.2787 & 1.0200 & 0.6929 & 1.5000 & & & \\
\hline \multirow[t]{2}{*}{ rs11989862 } & $\mathrm{T}$ & 66 & 69 & 0.2773 & 0.2899 & 1 & 1 & 1 & 0.0797 & 0.7778 & 0.7285 \\
\hline & $\mathrm{C}$ & 172 & 169 & 0.7227 & 0.7101 & 1.0550 & 0.7292 & 1.5250 & & & \\
\hline \multirow[t]{2}{*}{ rs352808 } & $\mathrm{C}$ & 80 & 89 & 0.3101 & 0.3450 & 1 & 1 & 1 & 0.7051 & 0.4011 & 0.4810 \\
\hline & $\mathrm{G}$ & 178 & 169 & 0.6899 & 0.6550 & 1.1700 & 0.8107 & 1.6880 & & & \\
\hline
\end{tabular}

HRR $=$ haplotype relative risk; TUSC3 = tumor suppressor candidate 3; 95\% Lo $=$ the $95 \%$ lower confidence level; $95 \% \mathrm{Hi}=$ the $95 \%$ upper confidence level.

LD analysis and haplotype structure were performed using Haploview version 4.1. Elevated LD was apparent between rs6530893 and rs6994908 sites, which constituted a haplotype block. The haplotypes with frequency $>0.05$ were included and analyzed in the following steps.

Haplotype analyses also demonstrated similar results using the TDT method (TDT: $\mathrm{T}-\mathrm{T}, \mathrm{P}=0.0011$, T-C, $\mathrm{P}=0.0461$ ) (Table 4 ). Upon further testing by multiple testing corrections, the association between the rs6530893-rs6994908 haplotype and ARMR in the Qinba mountain area remained significant (TDT: T-T FDR $q$ value $=0.0185$ ). This haplotype was subsequently tested for HRR analyses. The rs6530893-rs6994908 haplotype was also associated with ARMR in this region (HRR: $\mathrm{P}=0.0046$ ) (Table 5). The haplotype of rs6530893rs6994908 remained associated with ARMR in the Qinba mountain area after multiple testing 
corrections (HRR: FDR $q$ value $<0.05$ ). Power and sample size assessments indicated that the present sample size had $>85 \%$ power to detect the potential association between TUSC3 and ARMR in the Qinba mountain area in China.

Table 4. Haplotype TDT analysis results of rs6530893-rs6994908.
\begin{tabular}{lcccccc}
\hline Haplotypes $^{\mathrm{a}}$ & Frequency & Transmitted & Untransmitted & $\chi^{2}$ & $\mathrm{P}$ & $q$ \\
\hline T-T & 0.702 & 84.9 & 49.5 & 10.584 & 0.0011 & 0.0185 \\
T-C & 0.169 & 37.6 & 56.9 & 3.977 & 0.0461 & 0.0860 \\
C-C & 0.117 & 22.1 & 35.0 & 2.924 & 0.0873 & 0.1465 \\
\hline
\end{tabular}

TDT $=$ transmission disequilibrium test; ${ }^{a}$ Haplotypes with frequency lower than 0.05 were excluded from the P value calculation.

Table 5. Haplotype HRR test results of rs6530893-rs6994908.
\begin{tabular}{lcccccccccc}
\hline Haplotypes $^{\mathrm{a}}$ & Transmitted & Untransmitted & $\begin{array}{c}\text { Frequency of } \\
\text { transmission }\end{array}$ & $\begin{array}{c}\text { Frequency of } \\
\text { non-transmission }\end{array}$ & Odds ratio & $95 \%$ Lo & $95 \%$ Hi & $\chi^{2}$ & P & $q$ \\
\hline T-T & 172 & 134 & 0.8269 & 0.6442 & Reference & Reference & Reference & 8.0380 & 0.0046 & 0.0235 \\
T-C & 21 & 41 & 0.101 & 0.1971 & 0.613 & 0.3849 & 0.9761 & & & \\
C-C & 15 & 30 & 0.0721 & 0.1442 & 0.3791 & 0.1523 & 0.9436 & & & \\
\hline
\end{tabular}

$\mathrm{HRR}=$ haplotype relative risk; $95 \% \mathrm{Lo}=$ the $95 \%$ lower confidence level; $95 \% \mathrm{Hi}=$ the $95 \%$ upper confidence level. ${ }^{a}$ Haplotypes with frequencies lower than 0.05 were excluded from the calculation of $\mathrm{P}$ value.

\section{DISCUSSION}

MR is still one of the largest unresolved problems of human health care in the world. In the past decade, more than 450 genes were demonstrated to be associated with MR and related cognitive disorders (van Bokhoven, 2011). It is estimated that the total number of gene defects causing MR could run into the thousands (Inlow and Restifo, 2004). Although genomewide association studies and whole-exome sequencing have facilitated mutation screening, to date, only 13 loci and 10 genes have been identified to be associated with ARMR (Afroze and Chaudhry, 2013), i.e., PRSS12, CRBN, and TUSC3, among others. The reasons for the present state lie in the fact that relevant research has been performed in industrialized countries, where the large families required for efficient analyses are currently rare. MR is genetically heterogeneous, and validation of the causative role of the identified genes awaits confirmatory studies in other cohorts. Furthermore, the high frequency of failure to replicate results is fraught with disturbing population stratification. In contrast, the Qinba mountain area, located in northwest China, is isolated because of poor economic conditions and lack of transportation. The prevalence of MR $(2.78 \%)$ is higher than the average in China (1.07\%), and heritability is as high as $70.23 \%$ ( $\mathrm{Li}$ et al., 1999). Family-based association analysis can eliminate differences in genetic background and decrease population stratification problems (Altshuler et al., 2000; Laird and Lange, 2008). Thus, family-based association analyses were used to study the relationship between the TUSC3 gene and ARMR within this unique population base.

According to the TDT and HRR single-marker and haplotype analyses, both rs6530893 and rs6994908 were positively related to MR, which suggested that the TUSC3 gene might be associated with MR in the Qinba mountain area. The UCSC genome browser (http://genome. ucsc.edu/cgi-bin/hgGateway) showed that rs6530893 and rs6994908 were in proximity to 
each other, and located at either end of the sixth exon of the TUSC3 gene. Furthermore, in 2008, a research group reported that a French family existed with a single base pair insertion (c.787_788insC) in the sixth exon of the TUSC3 gene (Molinari et al., 2008), resulting in a premature stop codon, p.N263fsX300, and leading to mRNA decay. Therefore, the sixth exon may contribute to the risk of MR. Further studies on the sixth exon of the TUSC3 gene (e.g., mutation scanning/detection, functional analysis, etc.) in the Qinba mountain patients with MR should be conducted during the next phase of investigation.

MR is a frequent cause of cognitive disability (Ramakers, 2002). Recent studies have shown that the TUSC3 gene may be implicated in some pathways that are important for cognitive development. The TUSC3 gene has 11 exons and spans 224,265 bp of genomic DNA. It is expressed in a wide range of human tissues, including the brain. According to the UniProtKB database, the TUSC3 gene encodes a predicted 348-amino acid protein with five potential transmembrane domains. Ost3, its ortholog in yeast, encodes an oligosaccharyltransferase (OTase) that catalyzes the transfer of a 14-sugar oligosaccharide from dolichol to nascent proteins (Kelleher and Gilmore, 1994; MacGrogan et al., 1996). TUSC3 might also influence the etiology of MR through a similar mechanism. In the brain, the TUSC3 gene interacts with the alpha isoform of the catalytic subunit of protein phosphatase 1 (PPPC1A; MIM176875) (Rual et al., 2005), which plays a role in the modulation of synaptic and structural plasticity (Munton et al., 2004). In addition, protein phosphatase 1 also affects learning and memory (Genoux et al., 2002). Therefore, a suggested mechanism underlying MR might be the impairment of PPPC1A function. Alternatively, a recent study has revealed that TUSC3 is an indispensable member of the vertebrate plasma membrane magnesium ion $\left(\mathrm{Mg}^{2+}\right)$ transport system (Zhou and Clapham, 2009). An increase in the level of $\mathrm{Mg}^{2+}$ in the brain enhanced learning abilities, working memory, and short- and long-term memory in rats (Slutsky et al., 2010). Therefore, disturbed $\mathrm{Mg}^{2+}$ levels caused by TUSC3 impairment might also be responsible for the MR phenotype in patients.

There remain some controversial issues in studies on the role of the TUSC 3 gene in MR, including population stratification, false-positive discovery rates, and limited typical family size. Several previous studies had reported an important role of the TUSC3 gene in non-syndromic ARMR, within only one or more typical MR families, and covering different homozygous deletions that included the first or other exons of this gene (Garshasbi et al., 2008; Khan et al., 2011). However, as the genetic variants of TUSC3 underlying MR were still unknown, additional fine mapping work was needed. Nevertheless, Mhamdi et al. (2011) failed to explore the linkage between the TUSC3 gene and MR with the methods of polymorphic microsatellite and statistical analysis in four MR Tunisian families. Based on these limitations, we intended to determine whether TUSC 3 polymorphism was a risk factor for MR using a population sample rather than just a few consanguineous families.

To the best of our knowledge, our study is the first to evaluate TUSC 3 polymorphisms and their constructed haplotypes in relation to the risk of MR based on nuclear families in the Qinba mountain area. HRR and TDT analyses compared transmitted and non-transmitted genotypes determined through examination of parent/patient trios to provide a more robust association study of candidate genes, comparing traditional population case-control and linkage studies. Both the HRR and TDT methods can be used to analyze the same data and, thus, are alternative and complementary approaches to family-based association analysis (Schindler et al., 2001). The consistent results obtained using these two methods in this study also assured the reliability of our results. In addition, haplotype analysis may be more powerful than indi- 
vidual marker analyses (Akey et al., 2001), so haplotype analyses were performed following individual marker analysis. Finally, all the P values in the study were corrected using the Q value software based on false-discovery rates; thus, we could exclude the possibility of falsepositive results in our findings.

There are some limitations in the present study. For example, due to the relatively small sample size, further investigations using a larger sample are necessary to confirm the present findings. Another potential limitation is the absence of functional assays. Future research is needed to determine how the mutation in the sixth exon of TUSC3 functionally underlies a mechanism leading to MR.

In summary, our results suggest that the TUSC3 gene is associated with MR in the Qinba mountain area in China. In addition, the sixth exon of the TUSC3 gene may contribute to the risk of MR. Further detailed research on these factors will help to elaborate the pathogenesis of MR.

\section{ACKNOWLEDGMENTS}

Research supported by the National Natural Science Foundation of China (grants \#31371327 and \#31340028), a Project of Scientific Research Program funded by the Shaanxi Provincial Education Department (\#JH11241 and \#JH11282), and by the NWU Graduate Innovation and Creativity Funds (\#YZZ12054).

\section{REFERENCES}

Afroze B and Chaudhry B (2013). Genetics of non-syndromic autosomal recessive mental retardation. J. Pak. Med. Assoc. 63: 106-110.

Akey J, Jin L and Xiong M (2001). Haplotypes vs single marker linkage disequilibrium tests: what do we gain? Eur. J. Hum. Genet. 9: 291-300.

Altshuler D, Daly M and Kruglyak L (2000). Guilt by association. Nat. Genet. 26: 135-137.

Barrett JC, Fry B, Maller J and Daly MJ (2005). Haploview: analysis and visualization of LD and haplotype maps. Bioinformatics 21: 263-265.

Basel-Vanagaite L, Attia R, Yahav M, Ferland RJ, et al. (2006). The CC2D1A, a member of a new gene family with C2 domains, is involved in autosomal recessive non-syndromic mental retardation. J. Med. Genet. 43: 203-210.

Bashyam MD, Bair R, Kim YH, Wang P, et al. (2005). Array-based comparative genomic hybridization identifies localized DNA amplifications and homozygous deletions in pancreatic cancer. Neoplasia 7: 556-562.

Chen Y-F (2002). Chinese classification of mental disorders (CCMD-3): towards integration in international classification. Psychopathology 35: 171-175.

Didelot G, Molinari F, Tchénio P, Comas D, et al. (2006). Tequila, a neurotrypsin ortholog, regulates long-term memory formation in Drosophila. Science 313: 851-853.

Dudbridge F (2003). Pedigree disequilibrium tests for multilocus haplotypes. Genet. Epidemiol. 25: 115-121.

Garshasbi M, Hadavi V, Habibi H, Kahrizi K, et al. (2008). A defect in the TUSC3 gene is associated with autosomal recessive mental retardation. Am. J. Hum. Genet. 82: 1158-1164.

Garshasbi M, Kahrizi K, Hosseini M, Nouri Vahid L, et al. (2011). A novel nonsense mutation in TUSC3 is responsible for non-syndromic autosomal recessive mental retardation in a consanguineous Iranian family. Am. J. Med. Genet. A 155A: 1976-1980.

Genoux D, Haditsch U, Knobloch M, Michalon A, et al. (2002). Protein phosphatase 1 is a molecular constraint on learning and memory. Nature 418: 970-975.

Gong YX and Dai XY (1992). Chinese-Wechsler young children scale of intelligence (C-WYCSI). Hunan Map Press, Changsha.

Gong YX and Cai TS (1993). Wechsler intelligence scale for children, Chinese revision (C-WISC). Hunan Map Press, Changsha. 
Guruju MR, Lavanya K, Thelma B, Sujatha M, et al. (2009). Assessment of a clinical checklist in the diagnosis of fragile X syndrome in India. J. Clin. Neurosci. 16: 1305-1310.

Higgins JJ, Pucilowska J, Lombardi RQ and Rooney JP (2004). A mutation in a novel ATP-dependent Lon protease gene in a kindred with mild mental retardation. Neurology 63: 1927-1931.

Inlow JK and Restifo LL (2004). Molecular and comparative genetics of mental retardation. Genetics 166: 835-881.

Kelleher DJ and Gilmore R (1994). The Saccharomyces cerevisiae oligosaccharyltransferase is a protein complex composed of Wbp1p, Swp1p, and four additional polypeptides. J. Biol. Chem. 269: 12908-12917.

Khan MA, Rafiq MA, Noor A, Ali N, et al. (2011). A novel deletion mutation in the TUSC3 gene in a consanguineous Pakistani family with autosomal recessive nonsyndromic intellectual disability. BMC Med. Genet. 12: 56.

Krahn GL and Fox MH (2014). Health disparities of adults with intellectual disabilities: What do we know? What do we do? J. Appl. Res. Intellect. Disabil. 27: 431-446.

Laird NM and Lange C (2008). Family-based methods for linkage and association analysis. Adv. Genet. 60: 219-252.

Li F, Yan FT, Han Z and Yang WF (1999). A study of the relationship between health care during labour and children's mental retardation in QinBa mountain area, Shaanxi province. J. Xi' an Med. Univ. 20: 100-117.

Loddo S, Parisi V, Doccini V, Filippi T, et al. (2013). Homozygous deletion in TUSC3 causing syndromic intellectual disability: a new patient. Am. J. Med. Genet. A 161: 2084-2087.

Lubs HA, Stevenson RE and Schwartz CE (2012). Fragile X and X-linked intellectual disability: four decades of discovery. Am. J. Hum. Genet. 90: 579-590.

MacGrogan D, Levy A, Bova GS, Isaacs WB, et al. (1996). Structure and methylation-associated silencing of a gene within a homozygously deleted region of human chromosome band 8p22. Genomics 35: 55-65.

Mhamdi O, Kharrat M, Mrad R, Maazoul F, et al. (2011). Non-syndromic autosomal recessive mental retardation in Tunisian families: exclusion of GRIK2 and TUSC3 genes. Tunis. Med. 89: 479-484.

Millstein J, Conti DV, Gilliland FD and Gauderman WJ (2006). A testing framework for identifying susceptibility genes in the presence of epistasis. Am. J. Hum. Genet. 78: 15-27.

Molinari F, Rio M, Meskenaite V, Encha-Razavi F, et al. (2002). Truncating neurotrypsin mutation in autosomal recessive nonsyndromic mental retardation. Science 298: 1779-1781.

Molinari F, Foulquier F, Matthijs G, Gecz J, et al. (2008). Oligosaccharyltransferase-subunit mutations in nonsyndromic mental retardation. Am. J. Hum. Genet. 82: 1150-1157.

Motazacker MM, Rost BR, Hucho T, Garshasbi M, et al. (2007). A defect in the ionotropic glutamate receptor 6 gene (GRIK2) is associated with autosomal recessive mental retardation. Am. J. Hum. Genet. 81: 792-798.

Munton RP, Vizi S and Mansuy IM (2004). The role of protein phosphatase-1 in the modulation of synaptic and structural plasticity. FEBS Lett. 567: 121-128.

Noor A, Windpassinger C, Patel M, Stachowiak B, et al. (2008). CC2D2A, encoding a coiled-coil and C2 domain protein, causes autosomal-recessive mental retardation with retinitis pigmentosa. Am. J. Hum. Genet. 82: 1011-1018.

Ramakers GJ (2002). Rho proteins, mental retardation and the cellular basis of cognition. Trends Neurosci. 25: 191-199.

Rual JF, Venkatesan K, Hao T, Hirozane-Kishikawa T, et al. (2005). Towards a proteome-scale map of the human proteinprotein interaction network. Nature 437: 1173-1178.

Schindler K, Pato M, Dourado A, Macedo A, et al. (2001). Association and linkage disequilibrium between a functional polymorphism of the dopamine-2 receptor gene and schizophrenia in a genetically homogeneous Portuguese population. Mol. Psychiatr. 7: 1002-1005.

Slutsky I, Abumaria N, Wu LJ, Huang C, et al. (2010). Enhancement of learning and memory by elevating brain magnesium. Neuron 65: 165-177.

Storey JD and Tibshirani R (2003). Statistical significance for genomewide studies. Proc. Natl. Acad. Sci. U. S. A. 100: 9440-9445.

van Bokhoven H (2011). Genetic and epigenetic networks in intellectual disabilities. Annu. Rev. Genet. 45: 81-104.

Zhou H and Clapham DE (2009). Mammalian MagT1 and TUSC3 are required for cellular magnesium uptake and vertebrate embryonic development. Proc. Natl. Acad. Sci. U. S. A. 106: 15750-15755.

Zuo QH, Zhang ZX and Lei ZW (1988). Adaptive scale of infant and children. Medical University of China, Beijing. 